\title{
Glutamate functions in stomatal closure in Arabidopsis and fava bean
}

\author{
Riichiro Yoshida $^{1} \cdot$ Izumi C. Mori $^{2} \cdot$ Nobuto Kamizono $^{1} \cdot$ Yudai Shichiri $^{1} \cdot$ \\ Tetsuo Shimatani ${ }^{1} \cdot$ Fumika Miyata $^{1} \cdot$ Kenji Honda $^{1} \cdot$ Sumio Iwai $^{1}$
}

Received: 12 February 2015 / Accepted: 13 July 2015 / Published online: 19 November 2015

(C) The Botanical Society of Japan and Springer Japan 2015

\begin{abstract}
Guard cells are indispensable for higher plants because they control gas exchange and water balance to maintain photosynthetic activity. The signaling processes that govern their movement are controlled by several factors, such as abscisic acid (ABA), blue light, pathogenassociated molecular patterns (PAMPs), and carbon dioxide. Herein, we demonstrated that the amino acid glutamate (Glu), a well-known mammalian neurotransmitter, functions as a novel signaling molecule in stomatal closure in both Arabidopsis and fava bean (Vicia faba L.). Pharmacological and electrophysiological analyses provided important clues for the participation of Glu-receptors, $\mathrm{Ca}^{2+}$, and protein phosphorylation during the signaling process. Genetic analyses using Arabidopsis ABA-deficient (aba2-1) and ABA-insensitive (abil-1 and abi2-1) mutants showed that $\mathrm{ABA}$ is not required for Glu signaling. However, loss-of-function of the Arabidopsis gene encoding Slow Anion Channel-Associated 1 (SLACI) and Calcium-Dependent Protein Kinase 6 (CPKO) impaired the Glu response. Moreover, T-DNA knockout mutations of the Arabidopsis Glu receptor-like gene (GLR), GLR3.5, lost their sensitivity to Glu-dependent stomatal closure. Our results strongly support functional Glu-signaling in
\end{abstract}

Electronic supplementary material The online version of this article (doi:10.1007/s10265-015-0757-0) contains supplementary material, which is available to authorized users.

Riichiro Yoshida

ryoshida@agri.kagoshima-u.ac.jp

1 Laboratory of Horticultural Science, Faculty of Agriculture, Kagoshima University, 1-21-24 Kohrimoto, Kagoshima, Kagoshima 890-0065, Japan

2 Institute of Plant Sciences and Resources, Okayama University, 2-20-1, Chuo, Kurashiki 710-0046, Japan stomatal closure and the crucial roles of GLRs in this signaling process.

Keywords Arabidopis thaliana - Glutamate - Glutamate receptor $\cdot$ Signal transduction $\cdot$ Stomatal closure $\cdot$ Vicia $f a b a$

\section{Introduction}

The amino acid glutamate (Glu) plays pivotal roles in the functioning of the central nervous system in mammals (Watkins and Jane 2006). Glu-mediated signaling is initiated by the binding of Glu to several types of Glu receptors, including ionotropic Glu receptors (iGluRs) and metabotropic Glu receptors (mGluRs) (Mayer 2005). Plants do not have highly regulated nerve systems like animals, but families of Glu receptors homologous to mammalian iGluRs (GLRs) have been discovered in Arabidopsis (Lacombe et al. 2001; Lam et al. 1998), rice ( $\mathrm{Li}$ et al. 2006), and tomato (Aouini et al. 2012). Since the discovery of GLR genes in plant cells, Glu-signaling has been studied intensively as a potential amino acid sensor, and Glu was found to cause rapid membrane depolarization and $\mathrm{Ca}^{2+}$ flux in Arabidopsis roots (Dennison and Spalding 2000). Mutation of GLR3.3, one of 20 Arabidopsis genes, impaired both the membrane depolarization and the $\mathrm{Ca}^{2+}$ rise triggered by Glu (Qi et al. 2006). Moreover, Glu has been found to have several roles in plant signaling, which include regulating hypocotyl elongation (Dubos et al. 2003; Lam et al. 1998), sensing mineral nutrient status (Kim et al. 2001), resisting aluminum toxicity (Sivaguru et al. 2003), and regulating the carbon/nitrogen balance (Kang and Turano 2003), abscisic acid (ABA) synthesis (Kang et al. 2004), cold (Meyerhoff et al. 2005), root meristem function ( $\mathrm{Li}$ et al. 
2006; Walch-Liu et al. 2006), plant defense against pathogens (Vatsa et al. 2011), pollen tube development (Michard et al. 2011), and long-distance wound signaling (Mousavi et al. 2013).

Stomata are pores on the surface of leaves, and the opening and closing of these pores control the diffusion of gases into and out of plant tissues. Stomata are formed by pairs of guard cells that sense environmental signals such as light, humidity, carbon dioxide $\left(\mathrm{CO}_{2}\right)$, and pathogens, and also respond to hormones including $\mathrm{ABA}$, auxin, and ethylene (Melotto et al. 2006; Schroeder et al. 2001; Shimazaki et al. 2007; Shope et al. 2008). Numerous signaling components act in the induction of stomatal closure. Among them, $\mathrm{Ca}^{2+}$ is the important signaling molecule in guard cell signaling. An increase in the cytosolic $\mathrm{Ca}^{2+}$ concentration $\left(\left[\mathrm{Ca}^{2+}\right]_{\text {cyt }}\right)$ can transduce cellular responses to various biotic and abiotic stimuli, including light, gravity, oxidative stress, cold shock, drought, hormones, salt stress, and fungal elicitors (Berridge et al. 2003; Sanders et al. 2002). The plant hormone ABA causes increases in the $\left[\mathrm{Ca}^{2+}\right]_{\text {cyt }}$ in guard cells via $\mathrm{Ca}^{2+}$ influx through plasma membrane $\mathrm{Ca}^{2+}$-permeable channels and $\mathrm{Ca}^{2+}$ release from internal stores, resulting in stomatal closure (Kwak et al. 2003; MacRobbie 2000; Pei et al. 2000; Staxen et al. 1999). Cho et al. (2009) demonstrated that GLR3.1 participates in external $\mathrm{Ca}^{2+}$ influx into the cytosol as well as external $\mathrm{Ca}^{2+}$-induced stomatal closure, but they did not show whether Glu induces stomatal closure through GLRs.

In the current study, we examined the possibility that Glu plays a role in guard cell signaling. We found that Glu functions as a signal for stomatal closure in both Arabidopsis and fava bean. This response required Glu receptors, activation of plasma membrane $\mathrm{Ca}^{2+}$-permeable channels, and protein phosphorylation, as revealed by pharmacological, electrophysiological and genetic analyses. Loss-offunction analyses demonstrated that one of the Arabidopsis GLR genes, GLR3.5, plays a pivotal role in this guard cell signaling. This is the first report demonstrating Gluinduced stomatal closure in higher plants.

\section{Materials and methods}

\section{Plant materials and growth conditions}

Arabidopsis Columbia (Col) and Landsberg erecta (Ler) ecotypes were used. Arabidopsis mutant lines aba2-1, abi1-1, abi2-1, slac1-2, cpk6-1, and cpk6-2 were studied, and T-DNA insertion lines of $g l r 1.1$, glr1.2, glr1.4, glr3.3, glr3.5, and glr3.7 in the Col background were obtained from the Arabidopsis Biological Research Center (ABRC). Plants were grown in soil (1:1 Metromix:vermiculite) in a controlled environment at $23{ }^{\circ} \mathrm{C}$ with a 11-h light:13-h dark cycle. Seeds of fava bean (Vicia faba L. cv. House Ryousai) were purchased from Kyouwa Seed Co. (Chiba, Japan). Plants were grown in a growth chamber at $23{ }^{\circ} \mathrm{C}$ with a 16-h light:8-h dark cycle.

\section{Stomatal aperture measurements}

Epidermal strips were peeled from abaxial young, fully expanded leaves. Epidermal strips were floated in petri dishes (diameter, $9 \mathrm{~cm}$ ) containing opening medium A [10 mM MES-KOH (pH 6.15), $50 \mathrm{mM} \mathrm{KCl,} 0.1 \mathrm{mM}$ $\left.\mathrm{CaCl}_{2}\right]$ for Arabidopsis, or opening medium B [10 mM MES-KOH (pH 6.15), $50 \mathrm{mM} \mathrm{KCl]} \mathrm{for} \mathrm{fava} \mathrm{bean} \mathrm{and} \mathrm{were}$ kept for $2 \mathrm{~h}$ at $23{ }^{\circ} \mathrm{C}$ under light $\left(50 \mu \mathrm{mol} \mathrm{m}{ }^{-2} \mathrm{~s}^{-1}\right)$. The strips were then transferred to opening medium containing sodium glutamate, glycine, and/or the pharmacological reagents (AP-5, EGTA, BAPTA-AM) and kept for $3 \mathrm{~h}$ at $23{ }^{\circ} \mathrm{C}$ under light irradiation. For light-induced stomatal opening, Glu was applied to the epidermal strips after the $2 \mathrm{~h}$ of dark period and subsequently exposed to light for $3 \mathrm{~h}$. Following treatment, the stomata were photographed under a microscope (Eclipse E600; Nikon Corp. Tokyo, Japan) using a digital camera (Ds-L2, Nikon Corp.). Inner widths of stomatal pores were measured using a digital micro-analyzer (Japan Polaroid Digital Products, Tokyo). At least four strips containing 20 stomata were measured for each treatment. Experiments were repeated at least three times, and Student's $t$ test was used to assess significant differences.

\section{Patch-clamp analysis}

Calcium-permeable channel current $\left(I_{\mathrm{Ca}}\right)$ was recorded essentially as published previously and described below (Ye et al. 2013). Patch-clamp data were recorded using a MultiClamp 700B amplifier equipped a CV-7B headstage and pClamp software 10.3, and analyzed with Clampfit 10.3 software (Molecular Devices, Sunnyvale, California, USA). Guard cell protoplasts for patch-clamping were isolated from Arabidopsis (Col) as described by $\mathrm{Ye}$ et al. (2013).

The pipette solution contained $10 \mathrm{mM} \mathrm{BaCl}, 0.1 \mathrm{mM}$ dithiothreitol, $4 \mathrm{mM}$ EGTA and $10 \mathrm{mM}$ MES-Tris (pH 7.1), and the bath solution contained $100 \mathrm{mM} \mathrm{BaCl} 2,0.1 \mathrm{mM}$ dithiothreitol and $10 \mathrm{mM}$ MES-Tris ( $\mathrm{pH}$ 5.6). Osmolarity of the solutions was adjusted with sorbitol to 500 and $485 \mathrm{mmol} \mathrm{kg}^{-1}$, respectively. Recording was started $10 \mathrm{~min}$ after the establishment of whole cell configuration in the absence of glutamate in the bath solution and successively recorded in the presence of glutamate after perfusion with bath solution containing $10 \mathrm{mM}$ Glu. The voltage was ramped from -18 to $-218 \mathrm{mV}$ (after liquid junction potential compensation) with a ramp speed of $0.1 \mathrm{~V} \mathrm{~s}^{-1}$. The ramp voltage protocol was applied 10 times to obtain an 
Fig. 1 Glu induces stomatal closure in both Arabidopsis and fava bean. a Stomatal aperture of Arabidopsis (Col) after incubation with $\mathrm{ABA}$ $(10 \mu \mathrm{M})$ and Glu $(1 \mathrm{mM})$ for $3 \mathrm{~h}$. b Stomatal response of Arabidopsis ecotypes (Col, Ler) and fava bean exposed to the indicated concentration of Glu for $3 \mathrm{~h}$. c Effects of Glu (1 mM) on the light-induced stomatal opening in Arabidopsis (Col). Stomatal aperture after dark incubation (D) and subsequent light exposure without or with Glu (DL, DL + Glu) were measured. Each bar indicates the mean \pm S.D. of $80-120$ measurements. Statistical differences were detected using a two-tailed $t$ test $(* P<0.05$, $* * P<0.01, * * * P<0.001)$ a

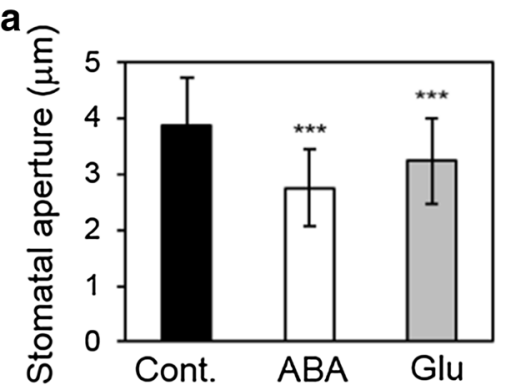

b

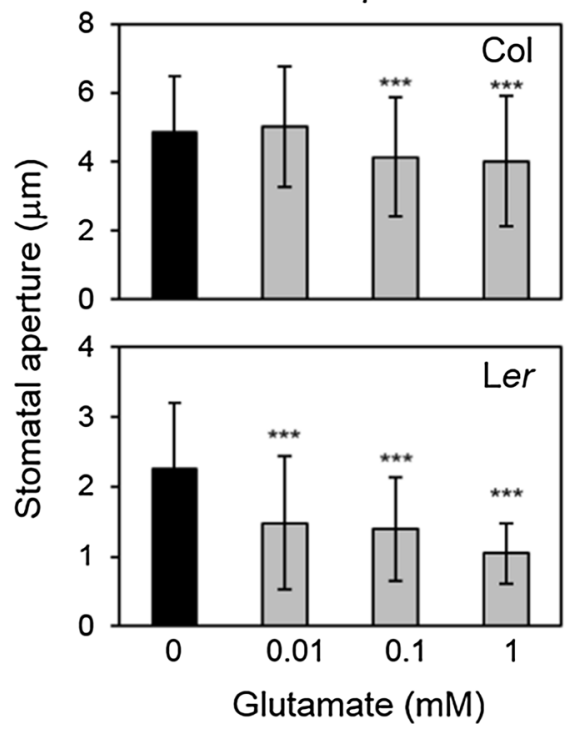

c
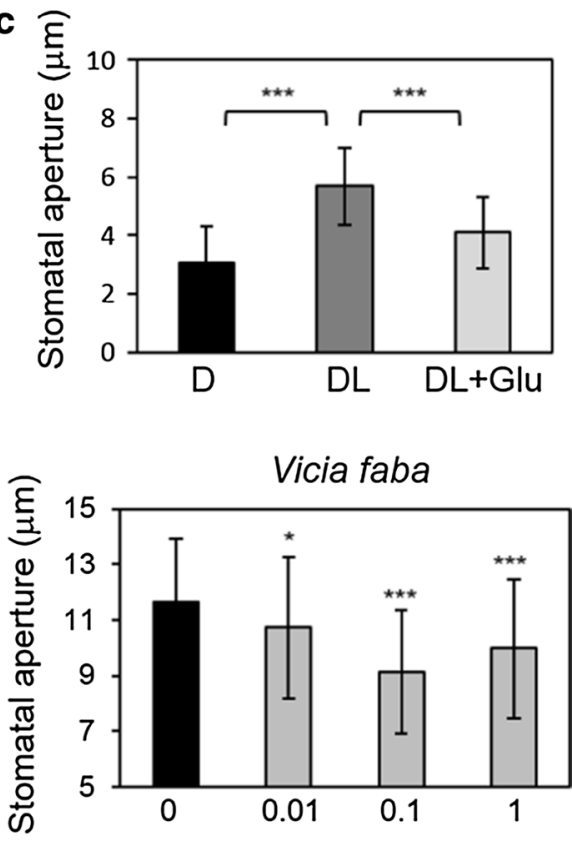

Glutamate (mM) average of a cell. Significance of difference between data sets was assessed by Wilcoxon signed ranks test.

\section{Purification of guard cell protoplasts}

Guard cell protoplasts were isolated enzymatically from the abaxial epidermis of approximately 100 rosette Arabidopsis leaves, as described previously (Pandey et al. 2002; Ueno et al. 2005). Purified guard cells were visually inspected for purity using a light microscope, and RNA was isolated immediately.

\section{RT-PCR}

Total RNA was extracted using TRIzol ${ }^{\circledR}$ (Invitrogen, Carlsbad, CA, USA). First strand cDNA was synthesized from $1 \mu \mathrm{g}$ of total RNA using ReveTra Ace ${ }^{\circledR}$ (Toyobo, Osaka, Japan) in a $10-\mu 1$ reaction mixture. RT-PCR was performed for 30-35 cycles using GoTaq ${ }^{\circledR}$ (Promega, Fitchburg, WI, USA). The primer sequences used in RT-PCR analysis were GLR3.5 Fw (GAGGAGCGAGGAGGCT), GLR3.5 Rv (AGTTTCGTGATCTTTCGACT), ACTIN2
Fw (GCCATCCAAGCTGTTCTCTC) and ACTIN2 Rv (GAACCACCGATCCAGACACT).

\section{Results}

Glu promotes stomatal closure in both Arabidopsis and fava bean

To ascertain whether Glu promotes stomatal closure, we applied sodium L-glutamate monohydrate to epidermal strips prepared from Arabidopsis and fava bean. As observed in ABA treatments, $1 \mathrm{mM}$ Glu potentiated stomatal closure in Arabidopsis (Fig. 1a). Next, we examined the effect of Glu on stomatal movement in Arabidopsis ecotypes and in fava bean. In the Columbia ecotype (Col), stomata started to close in response to $0.1 \mathrm{mM}$ Glu, but did not respond to $0.01 \mathrm{mM}$ Glu. In the Landsberg erecta ecotype (Ler), however, stomata closed even at $0.01 \mathrm{mM}$ Glu. Glu-induced stomatal closure was also observed in fava bean (Fig. 1b). We also examined whether Glu inhibits light-induced stomatal opening or not in Arabidopsis (Col). 
Fig. 2 Involvement of iGluRs in Glu-induced stomatal closure. a Effect of the iGluR antagonist AP-5 on Glu-induced stomatal closure in Arabidopsis and fava bean; $1 \mathrm{mM}$ and $0.1 \mathrm{mM}$ Glu were used in Arabidopsis and fava bean, respectively. The concentration of AP-5 was $1 \mathrm{mM}$. b Effect of $\mathrm{MgCl}_{2}$ on Glu-induced stomatal closure in Arabidopsis and fava bean; $1 \mathrm{mM}$ and $0.1 \mathrm{mM}$ Glu were used in Arabidopsis and fava bean, respectively. The concentration of $\mathrm{MgCl}_{2}$ was $5 \mathrm{mM}$. $\mathbf{c}$ Effect of Gly on Glu-induced stomatal closure; amino acids were applied separately or concurrently at 1 and $0.01 \mathrm{mM}$. Each bar indicates the mean \pm S.D. of $80-120$ measurements. Statistical differences were detected using a two-tailed $t$ test $(* P<0.05$, $* * P<0.01, * * * P<0.001)$
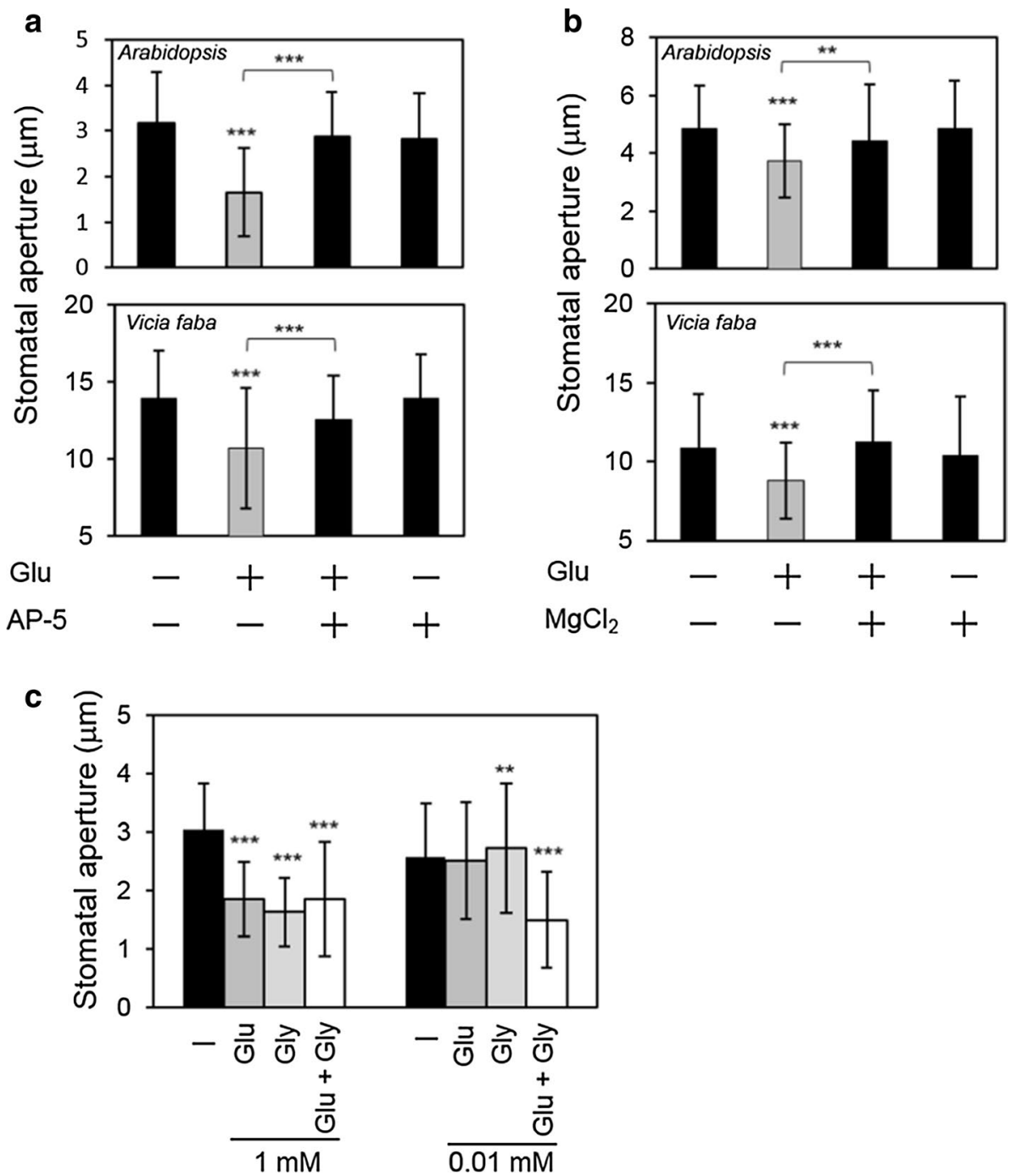

We found Glu not only induce stomatal closure, but also inhibit light-induced stomatal opening (Fig. 1c).

\section{Participation of Glu receptors in Glu-induced stomatal closure}

We used pharmacological reagents to probe the involvement of $N$-methyl-D-aspartate (NMDA)-type iGluRs in Glu-induced stomatal closure. Initially, we examined the effects of D-(-)-2-amino-5-phosphonopentanoic acid (AP5), a specific antagonist of NMDA GLRs, on Glu-induced stomatal closure. AP-5 inhibited Glu-induced stomatal closure in both Arabidopsis and fava bean (Fig. 2a). Magnesium chloride, which is known to block NMDA iGluR channels, suppressed the Glu-induced stomatal closure in both species (Fig. 2b). Since apoplastic concentration of free $\mathrm{Mg}^{2+}$ was shown to below $0.5 \mathrm{mM}$ in fava bean (Mühling and Sattelmacher 1995), $5 \mathrm{mM} \mathrm{Mg}^{2+}$ used in this experiment was reasonable for assessing the inhibitory effect of NMDA GLRs. Glycine (Gly), which functions as a iGluR agonist (Chatterton et al. 2002; Dubos et al. 2003; Ivanovic et al. 1998), induced stomatal closure at $1 \mathrm{mM}$ (Fig. 2c), but no additive effect of Gly and Glu was observed. A low concentration of Gly $(10 \mu \mathrm{M})$ alone did not induce stomatal closure. However, when $10 \mu \mathrm{M}$ Glu was applied with $10 \mu \mathrm{M}$ Gly, the stomata closed (Fig. 2c). These results suggested the participation of NMDA iGluRs in Glu-induced stomatal closure.

\section{$\mathrm{Ca}^{2+}$ is required for Glu-induced stomatal closure}

To further elucidate the possible relevance of GLRs in Glu-induced stomatal closure, we examined whether $\mathrm{Ca}^{2+}$ affects this signaling process. EGTA (extracellular $\mathrm{Ca}^{2+}$ chelator) and BAPTA-AM (intracellular $\mathrm{Ca}^{2+}$-chelator) inhibited the Glu-induced stomatal closure in Arabidopsis and fava bean, indicating that $\mathrm{Ca}^{2+}$ influx to the cytosol is required for this effect (Fig. 3a, b). We also examined 
Fig. $3 \mathrm{Ca}^{2+}$ is required for Glu-induced stomatal closure. a Effect of EGTA on Glu-induced stomatal closure in Arabidopsis and fava bean; 1 and $0.1 \mathrm{mM}$ Glu were used in Arabidopsis and fava bean, respectively. EGTA was used at 0.1 and $1 \mathrm{mM}$ in Arabidopsis and fava bean, respectively. $\mathbf{b}$ Effect of BAPTA-AM on Glu-induced stomatal closure in Arabidopsis and fava bean; 1 and $0.1 \mathrm{mM}$ Glu were used in Arabidopsis and fava bean, respectively. The concentration of BAPTAAM was $0.25 \mathrm{mM}$. c Effect of $\mathrm{LaCl}_{3}$ on Glu-induced stomatal closure in Arabidopsis and fava bean; 1 and $0.1 \mathrm{mM} \mathrm{Glu}$ were used in Arabidopsis and fava bean, respectively. The concentration of $\mathrm{LaCl}_{3}$ was $5 \mathrm{mM}$. Each bar indicates the mean \pm S.D. of $80-120$ measurements. Statistical differences were detected using a two-tailed $t$ test $(* P<0.05, * * P<0.01$, $* * * P<0.001)$
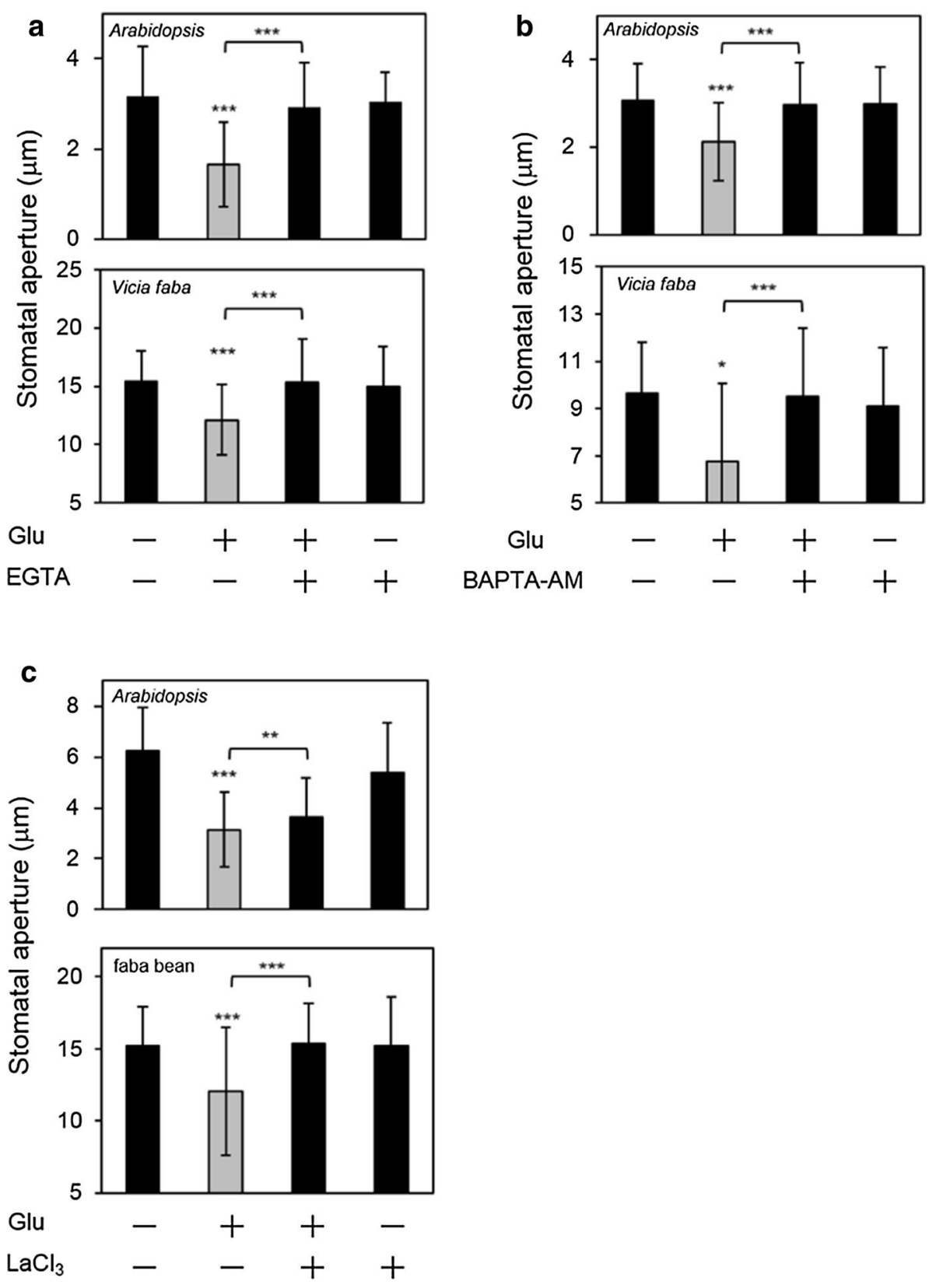

the effect of $\mathrm{LaCl}_{3}\left(\mathrm{Ca}^{2+}\right.$ channel blocker) on the Gluinduced stomatal closure. $\mathrm{La}^{3+}$ inhibited the Glu-induced stomatal closure in Arabidopsis and fava bean (Fig. 3c). These results indicated that $\mathrm{Ca}^{2+}$ influx occurred after Glu sensing.

\section{Glu activates plasma membrane $\mathrm{Ca}^{2+-}$ permeable channel currents $\left(I_{\mathrm{Ca}}\right)$ in Arabidopsis guard cells}

It has been shown that $I_{\mathrm{Ca}}$ of guard cells is activated by ABA, MeJA and microbe-associated molecular patters (Murata et al. 2015). Here we conducted patch-clamp analyses to examine activation of $I_{\mathrm{Ca}}$ by Glu application
(Fig. 4). In the absence of Glu small whole cell current $(-46 \pm 20 \mathrm{pA}$ at $-198 \mathrm{mV})$ was observed. The current was significantly activated by perfusion with $10 \mathrm{mM}$ Glucontaining bath solution to $-92 \pm 40 \mathrm{pA}$ at $-198 \mathrm{mV}$ $(P=0.046$, Wilcoxon signed ranks test, $n=6)$. These currents were substantially diminished by addition of $1 \mathrm{mM}$ $\mathrm{La}^{3+}(-18 \pm 5 \mathrm{pA}$ at $-198 \mathrm{mV})$. These results indicate that Glu activated ion current of which charge carrier was $\mathrm{Ba}^{2+}$ and capable to be blocked with $\mathrm{La}^{3+}$ similarly to ABA-activated $I_{\mathrm{Ca}}$ (Pei et al. 2000). The current amplitude appeared fairly variable among cells, while the reason was unresolved in this study. 


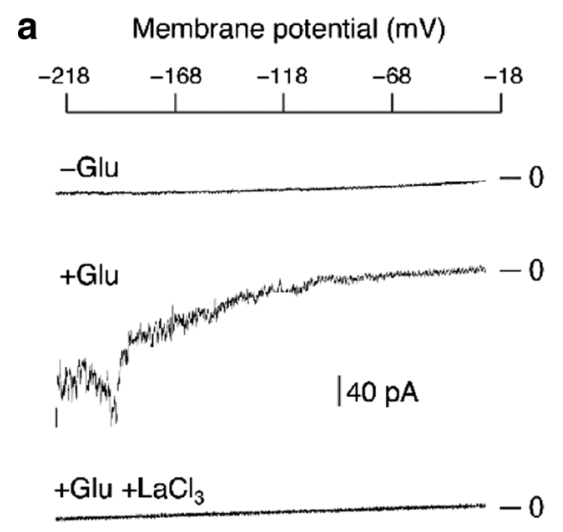

Fig. 4 Glu activation of $I_{\mathrm{Ca}}$ in plasma membrane of Arabidopsis guard cells. a Typical raw current traces; top horizontal scale indicates membrane voltage, and traces indicate typical whole cell current without Glu, with Glu $(10 \mathrm{mM})$ and with Glu $(10 \mathrm{mM})$ and $\mathrm{LaCl}_{3}(1 \mathrm{mM})$, respectively. Vertical scale bar indicates $40 \mathrm{pA}$. b

\section{Arabidopsis GLR3.5 is involved in Glu-induced stomatal closure}

The pharmacological experiments indicated the involvement of iGluRs in Glu-induced stomatal closure. To confirm the possibility, we used several T-DNA knockout lines of Arabidopsis GLRs and examined whether the mutations affect guard cell response to Glu. Arabidopsis has 20 GLR genes in its genome (Chiu et al. 2002; Roy et al. 2008). We obtained information on the expression of each GLR in Arabidopsis guard cells from the data published by Roy et al. (2008) and also from the Arabidopsis eFP Browser (http://bbc.botany.utoronto.ca/efp/cgi-bin/efpWeb.cgi). We estimated that the genes GLR1.1, GLR1.2, GLR1.4, GLR3.2, GLR3.3, GLR3.5, and GLR3.7 were expressed in guard cells, so we examined them further.

Among the seven lines tested, glr3.5 and glr3.7 impaired Glu-induced stomatal closure, whereas Glu induced stomatal closure in $g l r 1.1$, glr1.2, glr1.4, and glr3.3 (Fig. 5). We focused on GLR3.5. To ascertain whether GLR3.5 functions in guard cells, we prepared cDNA from guard cell protoplasts (GCPs) and confirmed its expression in these cells. The purity of GCPs was examined according to the expression of phosphoenolpyruvate carboxylase 2 (ATPPC2, At2g42600), which shows low-level expression in guard cells and high-level expression in mesophyll cells (Leonhardt et al. 2004), and hydroxyproline-rich protein (HPRP, At2g21140), which shows high-level expression in guard cells (Cho et al. 2009). We found a strong ATPPC2 signal in mesophyll cell cDNA compared with GCP cDNA (Fig. 6a). In contrast, HPRP was highly expressed in GCPs, but was scarce in mesophyll cells. As RT-PCR reflects the purity and specificity of GCP CDNA, we performed RTPCR analyses on GLR3.5 using GCP cDNA and examined b Membrane potential (mV)

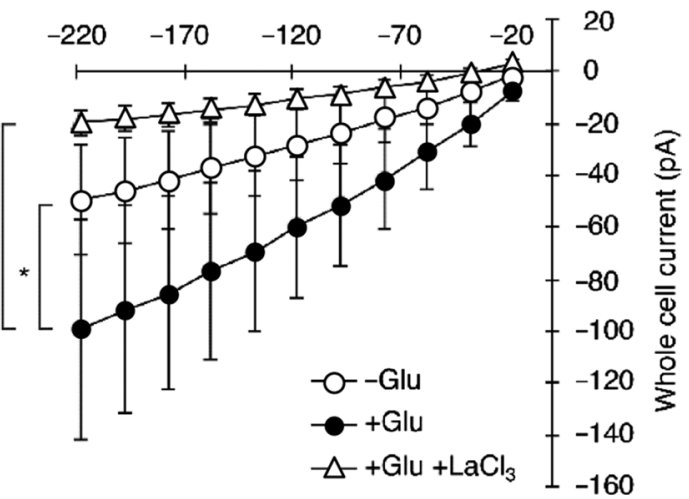

Averaged whole cell currents $(\mathrm{n}=6$ cells). Current from a cell was an average of 10 repeated records from a cell with 1-s intervals. Error bars represent SEM. Asterisks indicates significance (Wilcoxon signed ranks test, $\alpha=0.05$ )

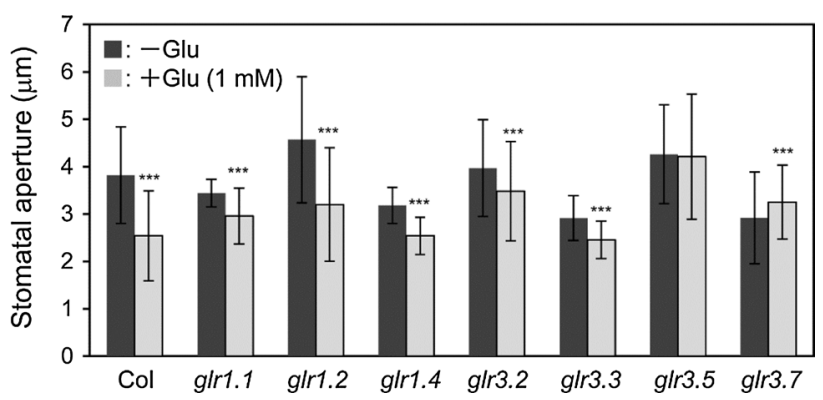

Fig. 5 Stomatal response of T-DNA GLR1.1, GLR1.2, GLR1.4, GLR3.2, GLR3.3, GLR3.5, and GLR3.7 knockout mutants. Expression of these genes was reported in guard cells (eFP Browser). These mutants were exposed to $1 \mathrm{mM}$ Glu. Each bar indicates the mean \pm S.D. of 80-120 measurements. Statistical differences were detected using a two-tailed $t$ test $(* P<0.05$, ** $P<0.01$, $* * * P<0.001)$

the expression in GCPs (Fig. 6b). We used two independent T-DNA lines, glr3.5-1 and glr3.5-2 (Fig. S1), and confirmed the disruption of this gene in these two lines via RT-PCR. Both lines showed impaired Glu-induced stomatal closure (Fig. 6c), whereas ABA and darkness induced stomatal closure (Fig. 6d, Fig. S2). These results suggest that GLR3.5 is expressed in guard cells and contributes to Glu-induced stomatal closure.

\section{Glu response does not mediate ABA signaling, but requires CPK6 and SLAC1 in an ABA-independent manner}

To clarify the signaling pathway leading to Glu-induced stomatal closure, we examined Glu-sensitivity in several Arabidopsis mutants having impaired guard cell responses. 
Fig. 6 Loss-of-function of the Arabidopsis GLR gene GLR3.5 prevented Glu-induced stomatal closure. a RT-PCR analysis of the mesophyll cell marker gene AtPPC2 and guard cell marker gene HPRP in guard cell protoplasts (GCPs) and leaf tissue. Total RNA $(1 \mu \mathrm{g})$ was prepared from GCPs and entire leaves for cDNA synthesis. b RT-PCR analysis of the GLR3.5 gene in GCPs. c Stomatal response of glr3.5-1 and glr3.5-2 mutants exposed to Glu (1 $\mathrm{mM})$. d Stomatal response of glr3.5-1 and $g l r 3.5-2$ mutants exposed to ABA $(10 \mu \mathrm{M})$. Each bar indicates the mean \pm S.D. of 80-120 measurements a

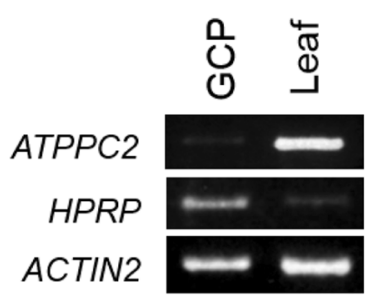

C

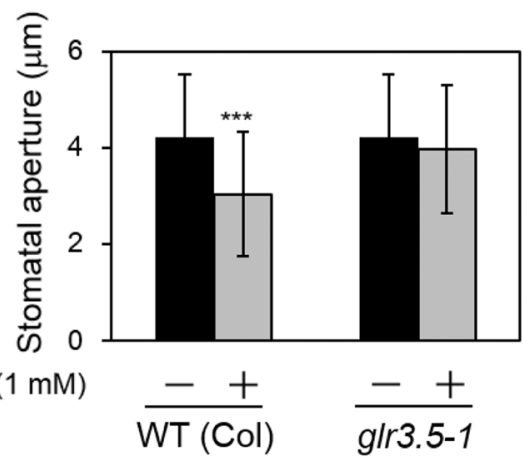

d

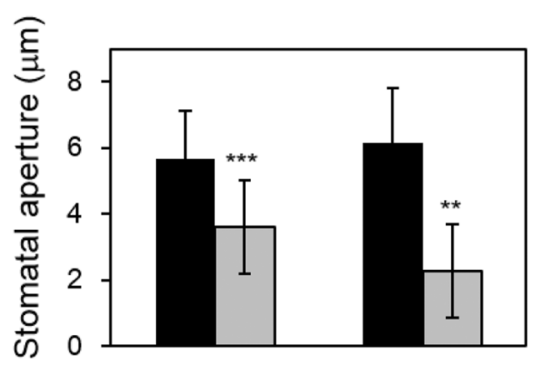

b
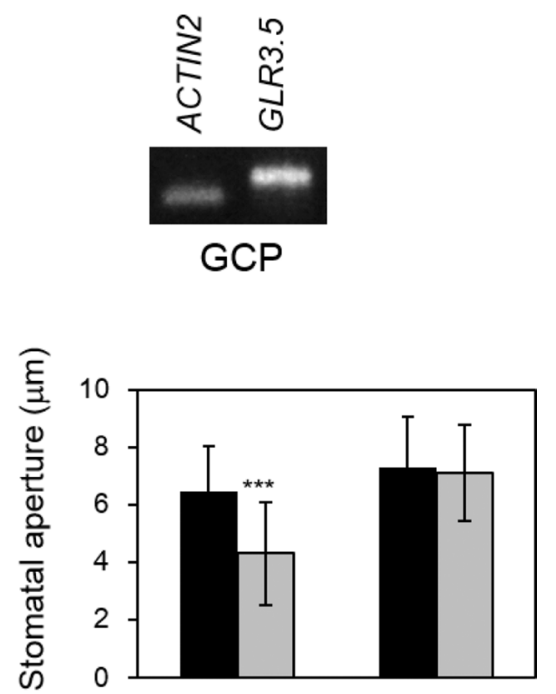

Glu (1 mM) $\frac{-+}{\text { WT (Col) }} \frac{-+}{\text { glr3.5-2 }}$

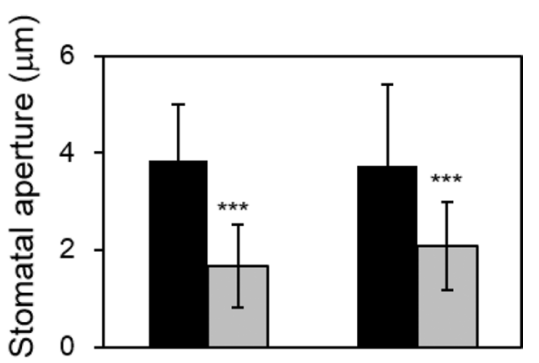

ABA $(10 \mu \mathrm{M}) \quad \frac{+}{\text { WT }(\mathrm{Col})} \quad \frac{-+}{\text { glr3.5-2 }}$
First, we tested the ABA-deficient mutant aba2-1 and the ABA-insensitive mutants abil-1 and abi2-1. Glu induced stomatal closure in these mutants (Fig. 7a, b), indicating that Glu signaling operates independently from ABA signaling in guard cells. We also used the slac1-2 mutant to ascertain whether this S-type anion channel gene, which has been shown to be involved in $\mathrm{CO}_{2}$ and $\mathrm{ABA}$ signaling (Xue et al. 2011), acts downstream of Glu-signaling. We found that slacl-2 lost its sensitivity for Glu-induced stomatal closure (Fig. 7c). Next, we examined whether protein phosphorylation is involved in Glu-dependent guard cell signaling. To address this question, we used protein kinase inhibitors of K252a and staurosporine. These reagents concurrently inhibited Glu-induced stomatal closure (Fig. 8a). The same concentration of solvent (dimethyl sulfoxide) used for dissolving these two inhibitors had no effect on Glu-dependent stomatal movement (Fig. S3). We also tested a loss-of-function mutation in Calcium Dependent Protein Kinase 6 (СРКб), which is a positive regulator of ABA-signaling (Mori et al. 2006). CPK6 has been shown to phosphorylate and activate SLAC1 protein (Brandt et al. 2012). We used two independent T-DNA knockout lines, cpk6-1 and cpk6-2. These mutants impaired Glu-induced stomatal closure (Fig. 8b), indicating that CPK6 protein kinase is involved in Glu-induced stomatal closure in an ABA-independent manner.

\section{Discussion}

Since the discovery of GLRs in the Arabidopsis genome (Lam et al. 1998), numerous studies have investigated Glu as a plant signaling molecule. Glu plays roles in, for example, the nitrogen to carbon balance (Kang and Turano 2003), regulation of ABA synthesis (Kang et al. 2004), control of root growth ( $\mathrm{Li}$ et al. 2006; Miller et al. 2010), and leaf-to-leaf wounding response (Mousavi et al. 2013). We assessed the possibility that Glu functions in guard cell signaling. In this study, we found that Glu induced stomatal closure in both Arabidopsis and fava bean in a 

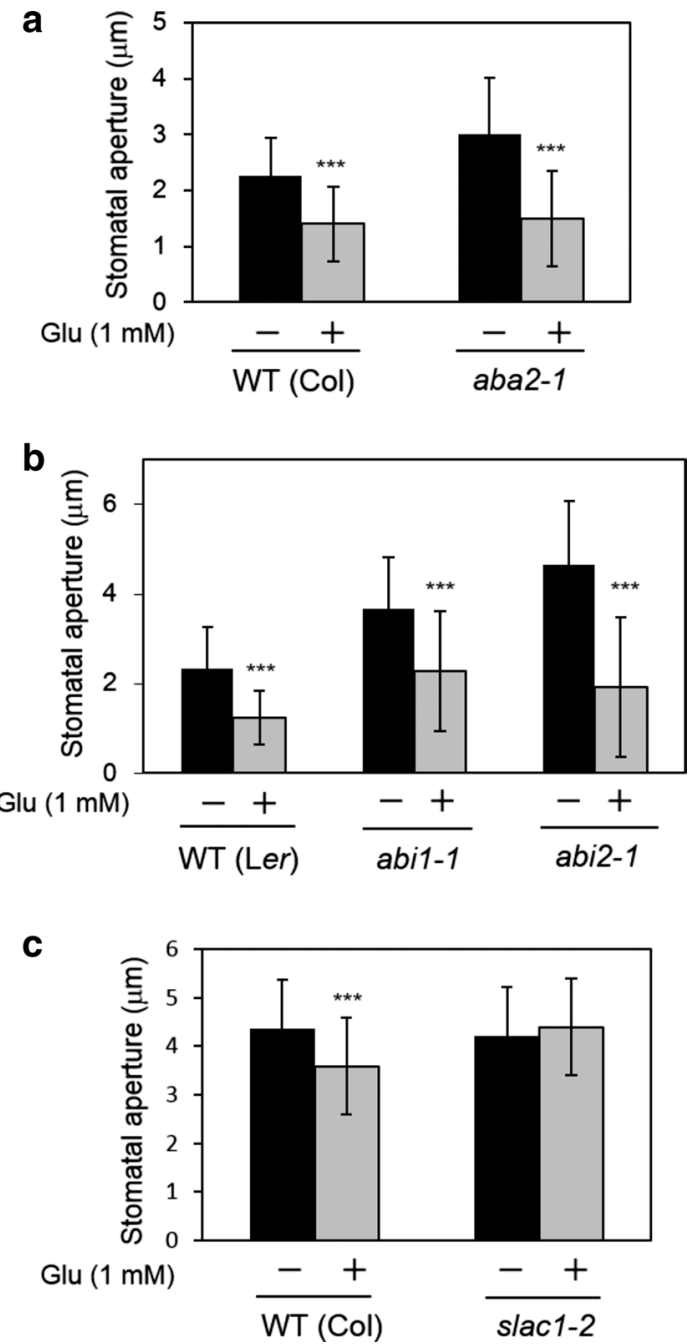

Fig. 7 Glu does not mediate ABA-signaling but requires SLAC1 in stomatal closure. a Stomatal response of the ABA-deficient mutant aba2-1 exposed to Glu ( $1 \mathrm{mM})$. b ABA-insensitive abil-1 and abi21 mutants exposed to Glu $(1 \mathrm{mM})$. Stomatal response of slacl-2 mutant exposed to Glu $(1 \mathrm{mM})$. Each bar indicates the mean \pm S.D. of 80-120 measurements. Statistical differences were detected using a two-tailed $t$ test $(* P<0.05, * * P<0.01, * * * P<0.001)$

dose-dependent manner. Pretreatment with a $\mathrm{Ca}^{2+}$ chelator and a $\mathrm{Ca}^{2+}$ channel blocker weakened Glu-induced stomatal closure. Furthermore, an antagonist and channel blocker of the NMDA receptor (AP-5, $\mathrm{Mg}^{2+}$ ) also inhibited Glu-induced stomatal closure. In contrast, glycine, which acts as an agonist of the NMDA receptor, promoted stomatal closure. Moreover, we have obtained direct evidence of Glu-dependent $\mathrm{Ca}^{2+}$ channel activity in guard cells by patch-clamp analysis. These results suggested that Glu indeed functions in guard cells and promotes stomatal closure through GLR-type $\mathrm{Ca}^{2+}$ channels in higher plants.

Previously, Arabidopsis GLR1.1 was shown to participate in stomatal movements (Kang et al. 2004). We showed that Glu normally induced stomatal closure in
GLR1.1 knockout mutant glr1.1, indicating that GLR1.1 is not involved in Glu-induced stomatal closure. In this study, we showed that another Arabidopsis GLR, GLR3.5, was expressed in guard cells and that its loss-of-function mutant impaired Glu-induced stomatal closure. These results indicated that GLR3.5 participates in Glu-induced stomatal closure, and we confirmed GLR3.7's involvement as well. Transcripts of GLR3.7 were found in guard cells, as revealed by RT-PCR analysis (data not shown). However, we could not prepare alternative knockout lines of this gene. We also tried to prepare $g l r 3.5 ; \mathrm{glr} 3.7$ double knockout mutant, however, these genes are tandemly located in chromosome II (GLR3.5: At2g32390; GLR3.7: At2g32400), and this made it difficult to produce double mutant. GLR channel may function as a heteromer and different combination of GLR subunit may specify its specific roles in different tissues or cells (Nicholas et al. 2008). It must be interesting if GLR3.5 and GLR3.7 form complex as a channel in guard cells. Future work will include experiments to identify other possible GLRs that function in Glu-dependent stomatal signaling.

Drought elicits the synthesis of ABA, which induces stomatal closure. Kang et al. (2004) reported that GLR1.1 regulates ABA synthesis, leading to the possibility that other GLRs also regulate ABA synthesis. We tested whether Glu affects stomata movements via ABA synthesis. In the ABAdeficient mutant $a b a 2-1$, Glu still induced stomatal closure. We also confirmed that Glu-induced stomatal closure was not abolished in the ABA-insensitive mutants abil-2 and abi2-1. Based on these results, we concluded that Glu elicits stomatal closure in an ABA-independent manner.

Calcium Dependent Protein Kinase 6 (CPK6) is a positive regulator in ABA-signaling, and it also regulates SLAC1 activity (Brandt et al. 2012; Mori et al. 2006). Once we had established that Glu-induced stomatal closure requires the activation of $\mathrm{Ca}^{2+}$ channels, protein phosphorylation, and SLAC1, we examined whether CPK6 controls Glu-induced stomatal response. We prepared two T-DNA knockout mutants of CPK6 and observed an impaired response to Glu-induced stomatal closure. This protein kinase phosphorylates and activates SLAC1 to trigger stomatal closure in a $\mathrm{Ca}^{2+}$-dependent manner (Brandt et al. 2012). Furthermore, CPK6 has been demonstrated to interact weakly with SLAC1 (Geiger et al. 2011). Given that SLAC1 was also involved in Glu-induced stomatal closure, Glu-dependent elevation of the cytosolic $\mathrm{Ca}^{2+}$ mayand activate CPK6 to promote SLAC1 activity. SLAC1 is also involved in cryptogein induced ion fluxes, ROS production, defense-related gene expression, and hypersensitive cell death in tobacco BY-2 cells (Kurusu et al. 2013), which may also support the presence of the functional Glu-signaling in guard cells. 
Fig. 8 Protein phosphorylation or calcium-dependent protein kinase $6(C P K 6)$ is prerequisite for Glu-induced stomatal closure. a Effect of protein kinase inhibitor K252a and staurosporine on Glu-induced stomatal closure in Arabidopsis; $1 \mathrm{mM}$ Glu and $1 \mu \mathrm{M} \mathrm{K} 252 \mathrm{a}$ and $1 \mu \mathrm{M}$ staurosporine were used. K252a and staurosporine were applied 30 min before Glu treatment. b Stomatal response of the wild type $(\mathrm{Col})$, and cpk6-1 and cpk6-2 mutants exposed to Glu (1 mM). Each bar indicates the mean \pm S.D. of $80-120$ measurements. Statistical differences were detected using a two-tailed $t$ test $(* P<0.05$, $* * P<0.01, * * * P<0.001)$ a
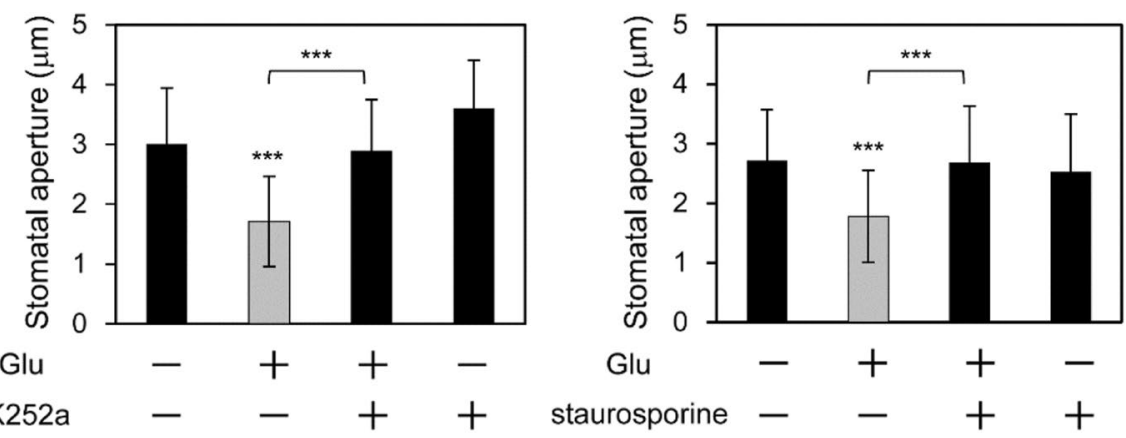

\section{b}

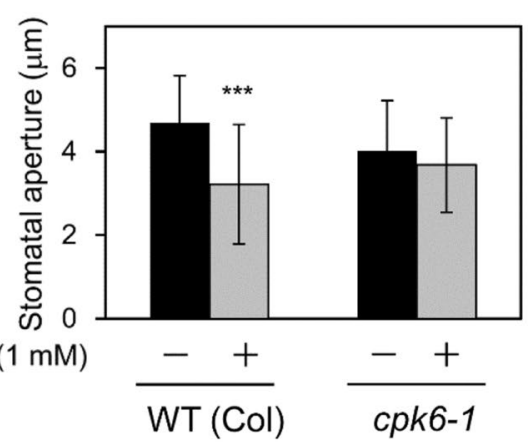

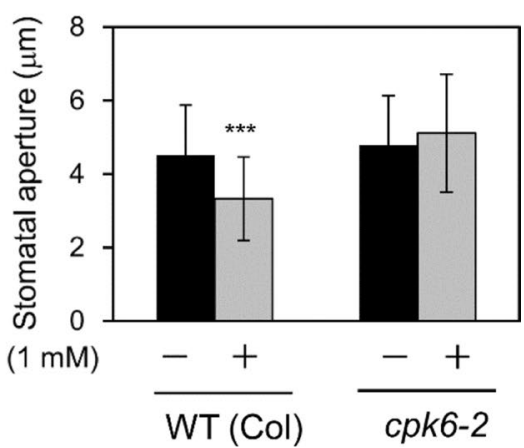

We propose a possible signaling cascade in Glu-induced stomatal closure (Fig. 9). Glu may activate GLR3.5 and trigger an increase in cytosolic $\mathrm{Ca}^{2+}$, which would then activate CPK6 in an ABA-independent manner, and then active CPK6 would elevate SLAC1 activity to induce stomatal closure. Several reports have indicated that protein phosphorylation, especially MAP kinase, is involved in Glu signaling. Application of Glu modulates MAMP-triggered MAP kinase activity and also affects MAMP-induced accumulation of defense gene transcripts in Arabidopsis (Kwaaitaal et al. 2011). Arabidopsis MAP kinase kinase kinase of MEKK1 plays a key role in Glu-induced root architecture (Forde et al. 2013). It must be interesting to examine whether or not MAP kinases are also involved in Glu-induced stomatal closure. Recently, Teardo et al. (2015) found that two isoforms of GLR3.5, isoform1 and isoform2, whose are derived from splicing variants are localized to mitochondria and chloroplast, respectively. Since mitochondria and chloroplast are known to play important roles in stomatal movement through modulating ROS, $\mathrm{NO}$ and $\mathrm{Ca}^{2+}$ signaling (Cvetkovska et al. 2014; Nomura et al. 2008; Weinl et al. 2008), Glu may changes the some physiological status of these two organelles through activating GLR3.5 (see Fig. 9).

Although we do not yet understand the precise biological roles of Glu-induced stomatal closure, some clues may support or explain the physiological relevance of Glu-signaling in guard cells. Vatsa et al. (2011) demonstrated that the plant pathogen elicitor cryptogein induces the release of Glu from plant cells by exocytosis and also increases

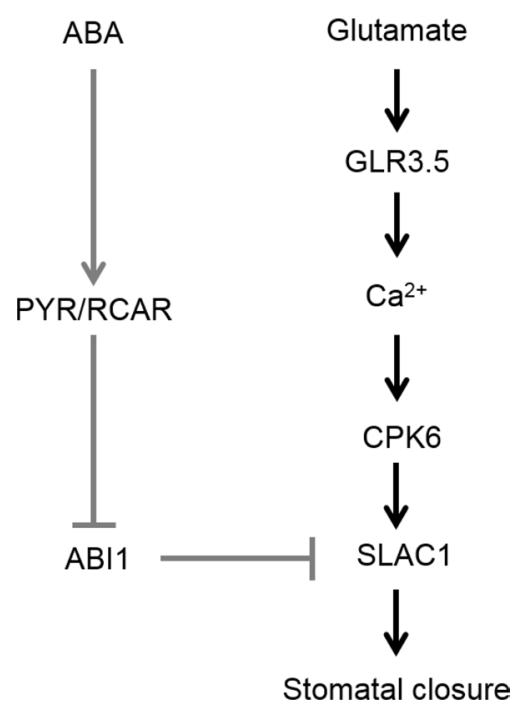

Fig. 9 Possible model of Glu signaling in stomatal closure. Glu activates Arabidopsis GLR3.5 and increases cytoplasmic $\mathrm{Ca}^{2+}$. Increased $\mathrm{Ca}^{2+}$ may activate CPK6 and subsequently activate anion channel SLAC1 to induce stomatal closure. ABA signaling does not participate in Glu signaling

cytosolic $\mathrm{Ca}^{2+}$. They also indicated that the Glu concentration in the apoplast is increased by $2.6 \mathrm{mM}$ after $5 \mathrm{~min}$ in cryptogein treatment. In addition to Glu, Gly was also found to present in the tomato leaf apoplast at a concentration around $0.2 \mathrm{mM}$ (Solomon and Oliver 2001). We tried to ascertain whether $0.2 \mathrm{mM}$ of Gly induces stomatal closure in Arabidopsis, however, any changes in stomatal 
movement were observed (Fig. S4). In contrast, we found that low concentration of $\mathrm{Glu}(0.1 \mathrm{mM})$ did induce stomatal closure in both Arabidopsis and fava bean (Fig. 1). We did not observe any additive effects of Glu and Gly on stomatal closure at the concentration of $1 \mathrm{mM}$ (Fig. 2). These results may reflect some physiological aspect of plant iGluRs in ligand efficacy. We do not have any information about whether the apoplastic concentration of Gly is increased or not by certain stimuli. Nevertheless, application of $1 \mathrm{mM}$ Gly was shown to trigger the elevation of cytosolic $\mathrm{Ca}^{2+}$ in Arabidopsis seedlings (Dubos et al. 2003). These studies may support the functional roles of Glu in guard cell signaling.

Stomata are one of the pores that plant pathogens can invade inside the leaf tissues, and several studies have demonstrated that pathogen elicitors trigger stomatal closure (Koers et al. 2011; Melotto et al. 2006). In addition, bacteria are capable of secreting Glu or Gly during their growth (Park et al. 2003). The Glu secreted from plant cells or bacteria may act on the epidermis and play a key role in the regulation of stomatal closure to restrict pathogen invasion. We will further examine whether exogenous Glu confers stomatal defense in higher plants.

Acknowledgments This work was supported in part by the Japan Society for the Promotion of Science Grant-in-Aid for Scientific Research (JSPS-KAKENHI; grant number 24570056).

\section{References}

Aouini A, Matsukura C, Ezura H, Asamizu E (2012) Characterisation of 13 glutamate receptor-like genes encoded in the tomato genome by structure, phylogeny and expression profiles. Gene 493:36-43

Berridge MJ, Bootman MD, Roderick HL (2003) Calcium signalling: dynamics, homeostasis and remodelling. Nature Rev Mol Cell Biol 4:517-529

Brandt B, Brodsky DE, Xue S, Negi J, Iba K, Kangasjärvi J, Ghassemian M, Stephan AB, Hu H, Schroeder JI (2012) Reconstitution of abscisic acid activation of SLAC1 anion channel by CPK6 and OST1 kinases and branched ABI1 PP2C phosphatase action. Proc Natl Acad Sci USA 109:10593-10598

Chatterton JE, Awobuluyi M, Premkumar LS, Takahashi H, Talantova M, Shin Y, Cui J, Tu S, Sevarino KA, Nakanishi N, Tong G, Lipton SA, Zhang D (2002) Excitatory glycine receptors containing the NR3 family of NMDA receptor subunits. Nature 415:793-798

Chiu JC, Brenner ED, DeSalle R, Nitabach MN, Holmes TC, Coruzzi GM (2002) Phylogenetic and expression analysis of the glutamate-receptor-like gene family in Arabidopsis thaliana. Mol Biol Evol 19:1066-1082

Cho D, Kim SA, Murata Y, Lee S, Jae SK, Nam HG, Kwak JM (2009) De-regulated expression of the plant glutamate receptor homolog AtGLR3.1 impairs long-term $\mathrm{Ca}^{2+}$-programmed stomatal closure. Plant J 58:437-449

Cvetkovska M, Dahal K, Alber NA, Jin C, Cheung M, Vanlerberghe GC (2014) Knockdown of mitochondrial alternative oxidase induces the 'stress state' of signaling molecule pools in Nicotiana tabacum, with implications for stomatal function. New Phytol 203:449-461

Dennison KL, Spalding EP (2000) Glutamate-gated calcium fluxes in Arabidopsis. Plant Physiol 124:1511-1514

Dubos C, Huggins D, Grant GH, Knight MR, Campbell MM (2003) A role for glycine in the gating of plant NMDA-like receptors. Plant J 35:800-810

Forde BG, Cutler SR, Zaman N, Krysan PJ (2013) Glutamate signaling via a MEKK kinase-dependent pathway induces changes in Arabidopsis root architecture. Plant J 75:1-10

Geiger D, Scherzer S, Mumm P, Marten I, Ache P, Matschi S, Liese A, Wellmann C, Al-Rasheid KA, Grill E, Romeis T, Hedrich R (2011) Guard cell anion channel SLAC1 is regulated by CDPK protein kinases with distinct $\mathrm{Ca}^{2+}$ affinities. Proc Natl Acad Sci USA 107:8023-8028

Ivanovic A, Reilander H, Laube B, Kuhse J (1998) Expression and initial characterization of a soluble glycine binding domain of the $N$-methyl-D-aspartate receptor NR1 subunit. J Biol Chem 273:19933-19937

Kang J, Turano FJ (2003) The putative glutamate receptor 1.1 (AtGLR1.1) functions as a regulator of carbon and nitrogen metabolism in Arabidopsis thaliana. Proc Natl Acad Sci USA 100:6872-6877

Kang J, Mehta S, Turano FJ (2004) The putative glutamate receptor 1.1 (AtGLR1.1) in Arabidopsis thaliana regulates abscisic acid biosynthesis and signaling to control development and water loss. Plant Cell Physiol 45:1380-1389

Kim SA, Kwak JM, Jae SK, Wang MH, Num HG (2001) Overexpression of the AtGluR2 gene encoding an Arabidopsis homolog of mammalian glutamate receptors impairs calcium utilization and sensitivity to ionic stress in transgenic plants. Plant Cell Physiol 42:74-84

Koers S, Guzel-Deger A, Marten I, Roelfsema MR (2011) Barley mildew and its elicitor chitosan promote closed stomata by stimulating guard-cell S-type anion channels. Plant J 68:670-680

Kurusu T, Saito K, Horikoshi S, Hanamata S, Negi J, Yagi C, Kitahata N, Iba K, Kazuyuki Kuchitsu K (2013) An S-type anion channel SLAC1 is involved in cryptogein-induced ion fluxes and modulates hypersensitive responses in tobacco BY-2 cells. PLoS One 8:e70623

Kwaaitaal M, Huisman R, Maintz J, Reinstädler A, Panstruga R (2011) Ionotropic glutamate receptor (iGluR)-like channels mediate MAMP-induced calcium influx in Arabidopsis thaliana. Biochemical J 440:355-365

Kwak JM, Mori IC, Pei ZM, Leonhardt N, Torres MA, Dangl JL, Bloom RE, Bodde S, Jones JD, Schroeder JI (2003) NADPH oxidase AtrbohD and AtrbohF genes function in ROS-dependent ABA signaling in Arabidopsis. EMBO J 22:2623-2633

Lacombe B, Becker D, Hedrich R, DeSalle R, Hollmann M, Kwak JM, Schroeder JI, Le Novère N, Nam HG, Spalding EP, Tester M, Turano FJ, Chiu J, Coruzzi G (2001) The identity of plant glutamate receptors. Science 292:1486-1487

Lam HM, Chiu J, Hsieh MH, Meisel L, Oliveira IC, Shin M, Coruzzi G (1998) Glutamate-receptor genes in plants. Nature 396:125-126

Leonhardt N, Kwak JM, Robert N, Waner D, Leonhardt G, Schroeder JI (2004) Microarray expression analyses of Arabidopsis guard cells and isolation of a recessive abscisic acid hypersensitive protein phosphatase 2C mutant. Plant Cell 16:596-615

Li J, Zhu S, Song X, Shen Y, Chen H, Yu J, Yi K, Liu Y, Karplus VJ, Wu P, Deng XW (2006) A rice glutamate receptor-like gene is critical for the division and survival of individual cells in the root apical meristem. Plant Cell 18:340-349

MacRobbie EA (2000) ABA activates multiple $\mathrm{Ca}^{(2+)}$ fluxes in stomatal guard cells, triggering vacuolar $\mathrm{K}^{(+)}\left(\mathrm{Rb}^{(+)}\right)$release. Proc Natl Acad Sci USA 97:12361-12368 
Mayer ML (2005) Glutamate receptor ion channels. Curr Opin Neurobiol 15:282-288

Melotto M, Underwood W, Koczan J, Nomura K, He SY (2006) Plant stomata function in innate immunity against bacterial invasion. Cell 126:969-980

Meyerhoff O, Müller K, Roelfsema MRG, Latz A, Lacombe B, Hedrich R, Dietrich P, Becker D (2005) AtGLR3.4, a glutamate receptor channel-like gene is sensitive to touch and cold. Planta 222:418-427

Michard E, Lima PT, Borges F, Silva AC, Portes MT, Carvalho JE, Gilliham M, Liu LH, Obermeyer G, Feijó JA (2011) Glutamate receptor-like genes form $\mathrm{Ca}^{2+}$ channels in pollen tubes and are regulated by pistil D-serine. Science 332:434-437

Miller ND, Durham Brooks TL, Assadi AH, Spalding EP (2010) Detection of a gravitropism phenotype in glutamate receptor-like 3.3 mutants of Arabidopsis thaliana using machine vision and computation. Genetics 186:585-593

Mori IC, Murata Y, Yang Y, Munemasa S, Wang YF, Andreoli S, Tiriac H, Alonso JM, Harper JF, Ecker JR, Kwak JM, Schroeder JI (2006) CDPKs CPK6 and CPK3 function in ABA regulation of guard cell S-type anion- and $\mathrm{Ca}^{(2+)}$-permeable channels and stomatal closure. PLoS Biol 4:e327

Mousavi SAR, Chauvin A, Pascaud F, Kellenberger S, Farmer EE (2013) GLUTAMATE RECEPTOR-LIKE genes mediate leaf-toleaf wound signaling. Nature 500:422-426

Mühling KH, Sattelmacher B (1995) Apoplastic ion concentration of intact leaves of field bean (Vicia faba) as influenced by ammonium and nitrate nutrition. J Plant Physiol 147:81-86

Murata Y, Mori IC, Munemasa S (2015) Diverse stomatal signaling and the signal integration mechanism. Annu Rev Plant Biol 66:369-392

Nicholas RS, Qi Z, Spalding EP (2008) Glutamate receptor subtypes evidenced by differences in desensitization and dependence on the GLR3.3 and GLR3.4 genes. Plant Physiol 146:529-538

Nomura H, Komori T, Kobori M, Nakahira Y, Shiina T (2008) Evidence for chloroplast control of external $\mathrm{Ca}^{2+}$-induced cytosolic $\mathrm{Ca}^{2+}$ transients and stomatal closure. Plant J 53:988-998

Pandey S, Wang XQ, Coursol SA, Assmann SM (2002) Preparation and applications of Arabidopsis thaliana guard cell protoplasts. New Phytol 153:517-526

Park S, Wolanin PM, Yuzbashyan EA, Lin H, Darnton NC, Stock JB, Silberzan P, Austin R (2003) Influence of topology on bacterial social interaction. Proc Natl Acad Sci USA 100:13910-13915

Pei ZM, Murata Y, Benning G, Thomine S, Klüsener B, Allen GJ, Grill E, Schroeder JI (2000) Calcium channels activated by hydrogen peroxide mediate abscisic acid signalling in guard cells. Nature 206:731-734

Qi Z, Stephens NR, Spalding EP (2006) Calcium entry mediated by GLR3.3, an Arabidopsis glutamate receptor with a broad agonist profile. Plant Physiol 143:963-971

Roy SJ, Gilliham M, Berger B, Essah PA, Cheffings C, Miller AJ, Davenport RJ, Liu LH, Skynner MJ, Davies JM, Richardson P, Leigh RA, Tester M (2008) Investigating glutamate receptor-like gene co-expression in Arabidopsis thaliana. Plant, Cell Environ 31:861-871

Sanders D, Pelloux J, Brownlee C, Harper JF (2002) Calcium at the crossroads of signaling. Plant Cell 14:S401-S417

Schroeder JI, Allen GJ, Hugouvieux V, Kwak JM, Waner D (2001) Guard cell signal transduction. Annu Rev Plant Physiol Plant Mol Biol 52:627-658

Shimazaki K, Doi M, Assmann SM, Kinoshita T (2007) Light regulation of stomatal movement. Annu Rev Plant Biol 58:219-247

Shope JC, Peak D, Mott KA (2008) Stomatal responses to humidity in isolated epidermes. Plant Cell Environ 31:1290-1298

Sivaguru M, Pike S, Gassmann W, Baskin TI (2003) Aluminum rapidly depolymerizes cortical microtubules and depolarizes the plasma membrane: evidence that these responses are mediated by a glutamate receptor. Plant Cell Physiol 44:667-675

Solomon PS, Oliver RP (2001) The nitrogen content of the tomato leaf apoplast increases during infection by Cladosporium fulvum. Planta 213:241-249

Staxen I, Pical C, Montgomery LT, Gray JE, Hetherington AM, McAinsh MR (1999) Abscisic acid induces oscillations in guardcell cytosolic free calcium that involve phosphoinositide-specific phospholipase C. Proc Natl Acad Sci USA 96:1779-1784

Teardo E, Carraretto L, Bortoli SD, Costa A, Behera S, Wagner R, Schiavo FL, Formentin E, Szabo I (2015) Alternative splicingmediated targeting of the Arabidopsis GLUTAMATE RECEPTOR3.5 to mitochondria affects organelle morphology. Plant Physiol 167:216-227

Ueno K, Kinoshita T, Inoue S, Emi T, Shimazaki K (2005) Biochemical characterization of plasma membrane $\mathrm{H}^{+}$-ATPase activation in guard cell protoplasts of Arabidopsis thaliana in response to blue light. Plant Cell Physiol 46:955-963

Vatsa P, Chiltz A, Bourque S, Wendehenne D, Garcia-Brugger A, Pugin A (2011) Involvement of putative glutamate receptors in plant defence signaling and NO production. Biochimie 93:2095-2101

Walch-Liu P, Liu LH, Remans T, Tester M, Forde BG (2006) Evidence that L-glutamate can act as an exogenous signal to modulate root growth and branching in Arabidopsis thaliana. Plant Cell Physiol 47:1045-1057

Watkins JC, Jane DE (2006) The glutamate story. Br J Pharmacol 147:S100-S108

Weinl S, Held K, Schlücking K, Steinhorst L, Kuhlgert S, Hippler M, Kudla J (2008) A plastid protein crucial for $\mathrm{Ca}^{2+}$-regulated stomatal responses. New Phytol 179:675-686

Xue S, Hu H, Ries A, Merilo E, Kollist H, Schroeder JI (2011) Central functions of bicarbonate in S-type anion channel activation and OST1 protein kinase in $\mathrm{CO}_{2}$ signal transduction in guard cell. EMBO J 30:1645-1658

Ye W, Muroyama D, Munemasa S, Nakamura Y, Mori IC, Murata Y (2013) Calcium-Dependent Protein Kinase CPK6 positively functions in induction by yeast elicitor of stomatal closure and inhibition by yeast elicitor of light-induced stomatal opening in Arabidopsis. Plant Physiol 163:591-599 